Article

\title{
The Impact of Disasters on a Heritage Tourist Destination: A Case Study of Nepal Earthquakes
}

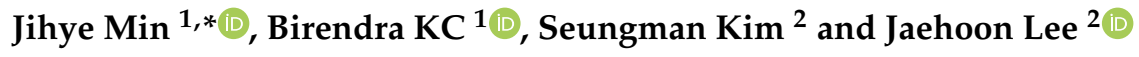 \\ 1 College of Merchandising, Hospitality and Tourism, University of North Texas, Chilton Hall 331, \\ 410 S Avenue C, Denton, TX 76201, USA; birendra.kc@unt.edu \\ 2 College of Education, Texas Tech University, 3002 18th Street, Lubbock, TX 79409, USA; \\ Seungman.kim@ttu.edu (S.K.); jaehoon.lee@ttu.edu (J.L.) \\ * Correspondence: jihye.min@unt.edu
}

Received: 5 July 2020; Accepted: 27 July 2020; Published: 29 July 2020

\begin{abstract}
This study examines the degree of macroeconomic recovery of the Nepal tourism industry after a natural disaster using the autoregressive integrated moving average model (ARIMA). The study investigated the case of Nepal's earthquakes in 2015 and examined the impact of the earthquakes on tourism inflows and GDP using time series data from 1990 to 2018. The results show that the increasing trend in the number of tourists changes in the post-earthquake period. In particular, the excess in tourist demand by age and purpose of visits after the earthquake indicates natural disaster as a potential reason for a tourism demand boost, often described as dark tourism in literature. This research shows the process of a heritage tourist destination assessing macroeconomic recovery from a natural disaster and fills the gap in the literature regarding purpose-based tourism demand and a link between dark tourism and disaster recovery on a heritage tourism destination.
\end{abstract}

Keywords: dark tourism; disaster economic impact; ARIMA; destination resilience; disaster recovery; heritage tourist destination; Nepal earthquakes; destination crisis management; disaster image restoration

\section{Introduction}

Any tourist destination can be affected by natural or man-made disasters. These disasters not only affect the image of destinations and experiences of the tourists but can also cause an unpredictable change in the economy. In 2015, an earthquake with a moment magnitude of 7.8 and aftershocks caused more than 9000 casualties and 22,000 injuries in Nepal, resulting in total economic loss of $\$ 5$ billion including the destruction of many heritage sites [1]. A decrease in tourist arrivals quickly followed, dropping from 79,187 tourists in March 2015 to 17,569 tourists in May 2015 [2]. While research in the economic literature has focused on the measurement of disaster impact $[3,4]$ and disaster management related to economic losses $[5,6]$, the resilience of a tourism destination from catastrophic events is largely unexplored in the literature. There is a limited amount of research that tries to embed tourists' motivations in a study involving natural disasters.

Nepal is a popular tourism destination which possesses many natural heritage areas including the world's highest mountain and cultural heritage areas listed on UNESCO sites, such as Kathmandu Valley and Lumbini, also known as the birthplace of Buddha [7]. The intactness of natural and cultural tourism resources throughout the country is a significant contributor and determinant of the international tourism demand and GDP [7]. According to the World Travel and Tourism Council's report, tourism has accounted for around 10\% of Nepal's GDP. Losses created from disaster caused significant drops in tourist arrivals which severely affected the economy [8]. 
Previous studies have emphasized long-term impacts of natural and man-made disasters on economic growth $[9,10]$ and have found a longer negative effect when the events resulted in injury or death to both tourists and residents [11]. Unlike previous research findings, recent tourism data released by the Nepal Tourism Board indicate an exponential growth in international tourist arrivals, surpassing the peak in 2014 by $48 \%$ [2]. This trend may be related to a short-term positive impact of reconstruction on economic growth $[12,13]$ and the increased number of tourists visiting sites that commemorate disasters, often referred to as dark tourism [14]. For instance, the terrorist attacks of 9/11 in New York in 2001 made the region the least popular place to visit, resulting in a $\$ 2$ billion drop in tourism revenue during the first week after the incident [15]. However, the memorial site after a decade had become one of the most popular world tourism attractions [16]. These sites may serve as a remembrance and a memorial site for victims [17], and the media attention towards a tragedy may contribute to the increased awareness and curiosity about the site.

With respect to the fact that Nepal is a popular natural and heritage tourism site, analyzing the impact of a natural disaster in accordance with tourists' motivations and the destination characteristics would be meaningful. Previous studies in the tourism literature related to Nepal earthquakes investigated the restoration of the destination image using a Facebook page [18], voluntary and accessible tourism [19,20], perceived benefits among local residents [21], and dark tourism [22]. These studies performed content analysis, observation, qualitative analysis, and a resident survey; thus, the economic analysis of the impact with tourists' characteristics provides contributions to the body of knowledge.

The purpose of this study is to examine how the occurrence of natural disasters shapes tourists' demand, numbers, and purpose of visits by analyzing secondary data published by Nepal Ministry of Culture, Tourism and Civil Aviation (NMCTCA) annually within the timeframe of 1990-2018. Additionally, key macroeconomic indicators, such as the GDP and tourism receipts, are analyzed to estimate the impact of earthquakes on tourism and the economy. Autoregressive integrated moving average (ARIMA) modeling with ordinary least squares (OLS) is utilized to analyze the data, and the modeling is useful in making short-term predictions and measuring effects $[12,13,23,24]$. This study is expected to provide an opportunity to explore how natural disasters affect heritage tourism sites and the recovery process. Moreover, this study is expected to quantify the impact of earthquakes on Nepal's tourism, economy, and the disaster resilience of a tourism destination.

\section{Literature Review}

\subsection{Resilience of Tourism Destinations}

Cultural heritage destinations often become vulnerable to natural disasters that pose threats to these destinations. There is a paucity of studies looking at the impact of natural disasters on cultural resources and tourism although this is even more critical when cultural destinations rely highly on tourism for economic development, for instance, Nepal. Several studies investigated the impact of natural disaster-led incidents on destinations and focused on tourism demand as a sole indicator $[24,25]$. Investigating pre- and post-effects of natural disasters on tourism demand can help us understand the resilience of the tourism destination. However, these studies often fail to correlate the impact of disasters on other macroeconomic indicators, such as GDP, tourism revenue, etc. For example, Guo et al. [26] conducted a study in two earthquake-affected tourism communities in China, in an attempt to understand the perceived resilience of the destination among residents using surveys. However, it is important to understand resilience of the destination based on factual figures, such as GDP and tourism receipts. Mair et al. [27] examined post-crisis recovery for tourist destinations using a meta-analysis. The study revealed that natural disasters cause damage to a destination's image and reputation, which can lead to bigger damage to the economy other than physical damage. Likewise, authors also mentioned that changing behaviors of tourists is a major concern in disaster-impacted destinations. Therefore, a focused post-disaster marketing strategy 
and management plan are necessary for the resilience of the destinations. Additionally, in a study examining the impact of a 7.3 Richter scale earthquake in 1999 on inbound tourism in Taiwan, the study found a prolonged recovery in tourism 11 months after the incident [24]. It is also important to note that the study used a univariate approach solely based on visitors' arrival data. Further, Mazzocchi and Montini [28] measured the effect of an earthquake on tourist demand in Italy and found an estimated financial loss of $\$ 71$ million in tourism within nine months of the incident. Meanwhile, authors echoed the importance of government policies and attitude towards the tourism industry as key factors for a successful recovery process. Tsai and Chen [25] also stressed the importance of disaster risk management strategies and guidelines for appropriate actions. Analyzing a disaster-recovery process at tourism destinations can set a precedent for disasters at other destinations. It can also help guide the formulation of a future disaster management plan. However, studies that examine the impact of disasters on tourist destinations are lacking. Particularly, there is a lack of research that examines the impact on destinations that are highly reliant on tourism, such as Nepal. Therefore, there is a need for empirical studies investigating how a disaster affects a unique tourism destination by incorporating tourism demand and other macroeconomic indicators.

\subsection{Theories Behind Dark Tourism}

Visiting places related to death, disaster, or suffering is often classified as dark tourism in literature [29]. Several scholars have described dark tourism as a form of postmodern tourism [30] and some argue that people's inherent fear of and interest in death has been expressed as this form of tourism [31]. Dark tourism sites provide opportunities for visitors to learn about the events and histories. With growing popularity, the sites have been increasingly commodified [32].

Scholars have suggested that understanding dark tourism motivations and experiences of tourists is complex as the root of this demand is related to numerous socio-psychological factors [33]. Although the area of research is still under-investigated, efforts have been made by scholars to identify factors that triggers tourists' desire to travel. The main factors identified by scholars were survivors' guilt, interests in death, empathy, remembrance, learning, entertainment, and novelty seeking $[22,34,35]$

From the theoretical aspects of dark tourism consumption, scholars have attempted to apply the concept of mortality mediation and terror management theory to explain dark tourism consumption [31]. The concept of mortality mediation is the best-known model, which conceptualizes the process of individuals neutralizing the impact of mortality [33,36,37]. According to Podoshen et al. [38], dark tourism provides individuals an opportunity to alleviate the fear of death and contemplate life with a sense of immortality. Later, Biran and Buda [39] applied terror management theory to explain the consumption of dark tourism and demonstrated how dark tourism serves as a buffer against the fear of death. According to the authors, implicit fear of death in one's mind is mediated by confronting the life-death issue through visiting dark tourism sites. This, in turn, stimulates one's self esteem and provides personal meaningfulness by escaping from one's everyday life and contemplating values in life. However, dark tourism consumption patterns may differ depending on one's visitation purpose and his or her life stage (age). While theories related to dark tourism enhance deeper understanding of personal motives and benefits of visiting the sites, there is a lack of insight into quantitative exploration of dark tourism in literature.

\subsection{Economic Impact of Disasters}

Scholars have confirmed the differing durations of economic recoveries from different catastrophic events. To assess the impact of natural disaster on an economy, scholars have used various macroeconomic indicators, such as GDP, employment, and unemployment rates [13]. GDP is the most frequently used indicator to measure macroeconomic resilience [40]. For instance, Hochrainer [23] employed GDP to investigate the economic impacts of 225 different natural disasters from 1960 to 2005 and confirmed the general trend of negative influence on the average economy. Raddatz [10] suggests that GDP would suffer from a long-term negative impact from natural disasters. In a study 
investigating hurricane effects on the U.S. economy, Zissimopoulos and Karoly [41] found similar employment and unemployment growth rates one year after Hurricane Katrina in 2005 to the rates before the hurricane in most affected regions. Chang [9] investigated the impact of the 1995 Kobe earthquake in Japan and found a recovery duration of six years for changes in populations and 91\% GDP recovery 10 years after the earthquake. Further, Raddatz [10] noted that lower-income countries or smaller countries felt a more severe negative economic impact due to natural disasters than higher-income countries or bigger countries. This also indicates that Nepal's economy would be more vulnerable to natural disasters than that of other countries.

Previous studies measured the degree of economic impact by comparing tourism demand preand post-disaster, or forecasting tourism demand, and applied various quantitative methods, such as ARIMA, vector auto-regression (VAR), OLS regression, and structural and econometric models [42]. VAR models were used in some studies to estimate the natural disaster impacts $[10,43]$ and an OLS model was used in Choi et al. [44]. OLS is useful in estimating unknown parameters for linear models [45]. However, ARIMA is considered more accurate in terms of making short-term predictions and measuring the effects $[12,13,23,24]$. A considerable number of researchers also used the number of tourist arrivals as a variable to measure the impacts of various disasters on tourism $[24,42,46,47]$. Kuo et al. [46] used ARIMA with exogenous inputs in a study investigating the impact of SARS by using tourist arrivals in Asia. In another study that evaluated the impact of earthquakes, Huang and Min [24] employed a seasonal ARIMA model, and predicted the visitors' arrivals and compared the predicted values to the actual tourist arrivals. Haque and Haque [42] adopted the ARIMA model and analyzed the effect of swine flu in Brunei.

Based on previous studies in the area, this study proposes that tourism is a vital part of the economic status of a country and represents economic resilience. Based on different findings from literature, a destination itself holds unique characteristics which would influence the process of disaster recovery and destination resilience. Therefore, in this study, macroeconomic indicators related to tourism such as GDP, tourism receipts, tourism arrivals, and purpose of visits are analyzed to measure the economic resilience of a heritage tourism destination after the Nepal earthquake in 2015. The impact of the earthquake is measured using ARIMA with OLS modeling to see how earthquakes affect tourism and economic resilience. This paper is going to provide a unique view by analyzing the macroeconomic recovery of a heritage tourism destination. The study also adds to the limited literature that explores the impact of natural disasters on a heritage tourism destination and explores the resilience of the destination, tourism demand, and growth following the impact.

\section{Methods}

\subsection{Data Source and Variables}

In this study, two types of secondary data were analyzed to examine the impact of the 8.1 magnitude earthquake, which occurred in Nepal in April 2015, on tourism: (1) the number of tourist arrivals in Nepal from 1993 to 2018 and the purpose of the visits, and (2) Nepal's tourism receipts and GDP from 1995 to 2018 . The yearly number of arrivals was grouped by the tourists' age: $0-15,16-30,31-45,46-60$, or over 60 years old. It was also categorized by tourists' visiting purposes: holiday pleasure, trekking and mountaineering, business, pilgrimage, official, and others. Tourism accounts for a substantial proportion (10.4\%) of Nepal's GDP [8]. Thus, both tourism receipts and GDP were chosen as key economic indicators to investigate the impact of the earthquake on tourism and the economy of Nepal. 


\subsection{Data Analysis}

Given the equally spaced time series data, ARIMA modeling techniques were utilized to estimate the effects of the earthquake on the number of tourist arrivals, different age groups and visiting purposes, as well as the tourism receipts and GDP. The ARIMA model can be written as:

$$
y_{t}=\alpha_{t}+\beta_{1 t} \text { time }+\beta_{2 t} \text { earthquake }+\beta_{3 t} \text { time } \cdot \text { earthquake }+\mu_{t}
$$

where $y_{t}$ denotes the study variable (dependent variable); $\alpha_{t}$ denotes the intercept; and $\beta_{1 t}, \beta_{2 t}, \beta_{3 t}$ respectively denote the slopes for time (year), earthquake indicator (yes $=1$, no $=0$ ), and interaction between time and earthquake indicator. When the dependent variable was the number of tourist arrivals, the earthquake indicator was coded as 0 for the years from 1993 to 2014 or 1 for the years from 2015 to 2018. In the case of the economical indicators, a rapid change occurred one year after the earthquake rather than at the year (2015) of the event (see Figures 1 and 2). Thus, when the dependent variable was tourism receipts or GDP, the earthquake indicator was coded as 0 from 1995 to 2015 or 1 for the years from 2016 to 2018 to enhance the explicability of the models.

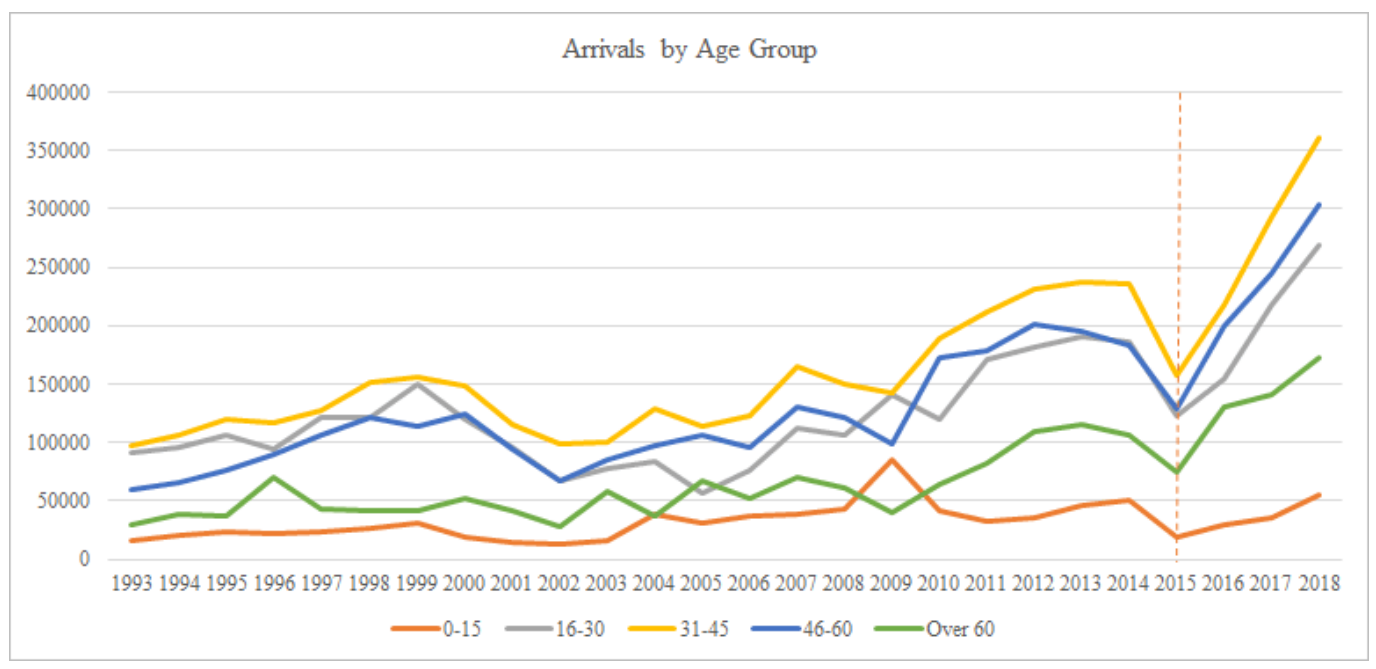

Figure 1. The number of tourist arrivals in Nepal from 1993 to 2018 by age group. The red dotted line indicates the year when the earthquake occurred (2015).

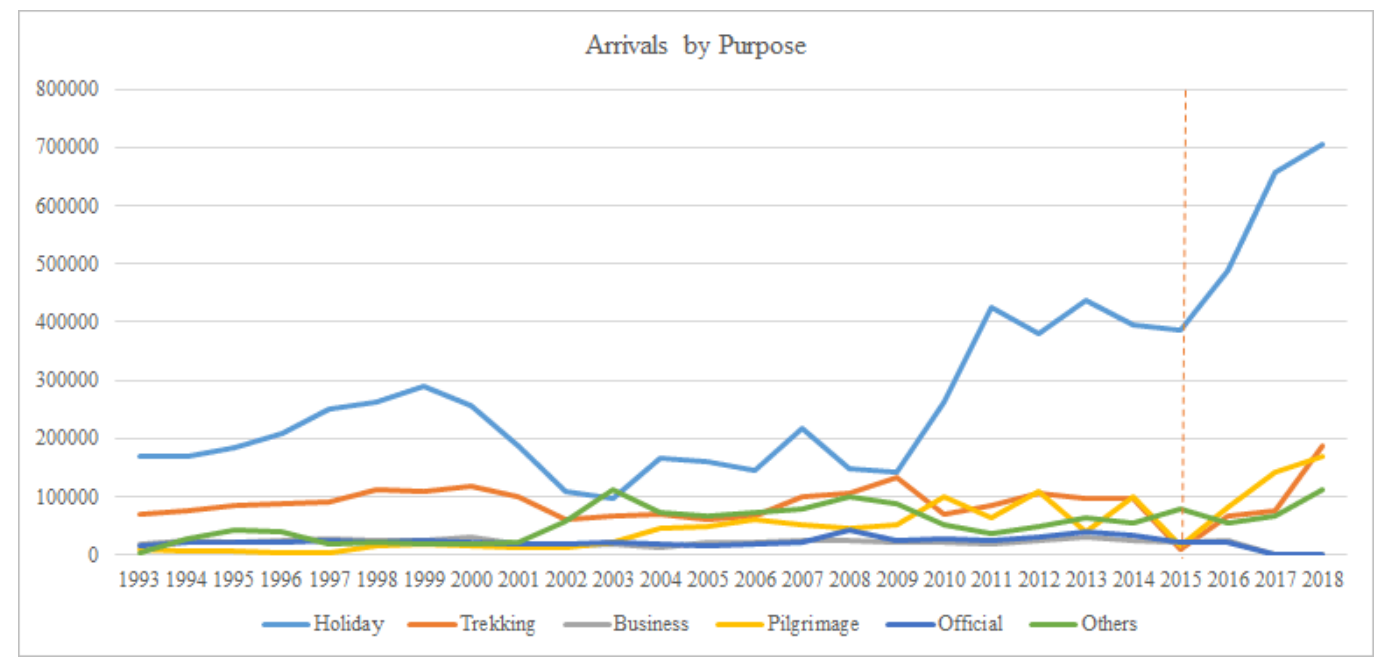

Figure 2. The number of tourist arrivals in Nepal from 1993 to 2018 by visiting purpose. The red dotted line indicates the year when the earthquake occurred (2015). 
In the above equation, $\mu_{t}$ captures the prediction error of the models. Assuming heteroskedastic errors across the time series, a first-order autoregressive, first-order moving-average error structure (ARIMA[1,0,1]) was specified as such:

$$
\mu_{t}=\phi_{1} \mu_{t-1}+\varepsilon_{t}-\theta_{1} \varepsilon_{t-1}
$$

where $\varphi_{1}$ denotes the vector of autoregressive coefficients; $\theta_{1}$ denotes the vector of moving-average coefficients; and $\varepsilon_{t}$ is assumed to be independently and identically distributed with an expected value of zero. Our inspection via autocorrelation plots and diagnostic statistics confirmed that this error structure was most appropriate compared to other alternative structures-for example, ARIMA[1,0,1] produced the lowest values of Akaike Information Criterion (AIC), AIC Corrected (AICC), and Bayesian Information Criterion (BIC) in the model for the total number of tourist arrivals (see Table 1). All analyses were conducted using SAS 9.4.

Table 1. ARIMA model fit for the total number of tourist arrivals, with different error structures.

\begin{tabular}{cccc}
\hline Error Structure & AIC & AICC & BIC \\
\hline Homoscedastic error structure & 691.0 & 2095.0 & 657.1 \\
First-order autoregressive moving-average & 649.8 & 654.3 & 642.0 \\
First-order autoregressive & 651.6 & 656.1 & 643.8 \\
Compound symmetry & Infinite likelihood reported \\
\hline
\end{tabular}

\section{Results}

Figures 1 and 2 depict the number of tourist arrivals from 1993 to 2018, by age group and visitation purpose. In general, the number of arrivals gradually increased after 1993 but sharply decreased in 2015 when the earthquake occurred. Interestingly, after the earthquake, the number of arrivals increased again and even exponentially with a higher rate compared to the years before the earthquake. This pattern of change was more evident for adult groups (16-60 years old) and for leisure visits.

The rapid recovery in the number of tourist arrivals was confirmed by the ARIMA modeling results (see Table 2). The interaction between time and earthquake was significant for the total number of arrivals $(p<0.001)$, indicating that the increase in the yearly number of international visitors was significantly greater after the earthquake than before the tragic event. The simple slopes derived from the model parameter estimates showed that the average yearly gain was 21,594 for the period before the earthquake (1993-2014) and 195,416 for the period after the earthquake (2016-2018). When the number of arrivals was broken down by age group, similar results were found. That is, the interaction term was significant for the age groups of $16-30,31-45,46-60$, and over 60 years old $(p<0.001)$. The difference in the average yearly gain before and after the earthquake was $45,223,60,286,52,266$, and 28,286 for the four age groups, respectively. However, the number of international visitors who were 15 years old or younger was not significantly affected by the occurrence of the earthquake.

As shown in Table 3, interaction between time and earthquake was significant for the number of visits for holiday pleasure, trekking and mountaineering, business, pilgrimage, and official (all $p<0.001$ ). In the case of holiday pleasure, trekking and mountaineering, and pilgrimage, the direction of the interactions (i.e., regression coefficients) was positive, indicating that the rate of increase was significantly higher for the period after the earthquake than for the period before the event. However, in the case of business and official, the number of international visits had decreased after the earthquake. The differences in the average yearly gain before and after the earthquake were $924,190,55,862,-10,719$ (decrease), 48,451, and -9099 (decrease) for holiday pleasure, trekking and mountaineering, business, pilgrimage, and official, respectively. 
Table 2. Autoregressive integrated moving average (ARIMA) modeling results for the number of tourist arrivals by age group.

\begin{tabular}{|c|c|c|c|c|c|}
\hline Age Group & Effect & Estimate & $S E$ & $t$ & $p$ \\
\hline \multirow[t]{4}{*}{ All } & Intercept & $264,774.00$ & $67,060.00$ & 3.95 & 0.010 \\
\hline & Time & $21,594.00$ & $516,012.00$ & 4.18 & 0.005 \\
\hline & Earthquake & $-4,508,702.00$ & $731,908.00$ & -6.16 & $<0.001$ \\
\hline & Time $\times$ earthquake & $195,416.00$ & $31,301.00$ & 6.24 & $<0.001$ \\
\hline \multirow{4}{*}{$\begin{array}{c}0-15 \text { years old } \\
\left(d f: 2, \chi^{2}: 32.38, p: 0.481\right)\end{array}$} & Intercept & $14,718.00$ & 5192.45 & 2.83 & 0.032 \\
\hline & Time & 1643.09 & 421.73 & 3.90 & 0.008 \\
\hline & Earthquake & $-249,811.00$ & $120,433.00$ & -2.07 & 0.050 \\
\hline & Time $\times$ earthquake & 9857.56 & 5130.63 & 1.92 & 0.068 \\
\hline \multirow{4}{*}{$\begin{array}{c}16-30 \text { years old } \\
\left(d f: 2, \chi^{2}: 19.42, p:<0.001\right)\end{array}$} & Intercept & $80,768.00$ & $22,554.00$ & 3.58 & 0.019 \\
\hline & Time & 3870.48 & 1715.37 & 2.26 & 0.065 \\
\hline & Earthquake & $-1,040,455.00$ & $242,878.00$ & -4.28 & $<0.001$ \\
\hline & Time $\times$ earthquake & $45,223.00$ & $10,387.00$ & 4.35 & $<0.001$ \\
\hline \multirow{4}{*}{$\begin{array}{c}31-45 \text { years old } \\
\left(d f: 2, \chi^{2}: 24.25, p:<0.001\right)\end{array}$} & Intercept & $90,151.00$ & $17,643.00$ & 5.11 & 0.002 \\
\hline & Time & 5745.37 & 1388.01 & 4.14 & 0.005 \\
\hline & Earthquake & $-1,383,432.00$ & $236,976.00$ & -5.84 & $<0.001$ \\
\hline & Time $\times$ earthquake & $60,286.00$ & $10,119.00$ & 5.96 & $<0.001$ \\
\hline \multirow{4}{*}{$\begin{array}{c}46-60 \text { years old } \\
\left(d f: 2, \chi^{2}: 10.90, p: 0.004\right)\end{array}$} & Intercept & $60,774.00$ & $15,174.00$ & 4.01 & 0.008 \\
\hline & Time & 5446.16 & 1200.16 & 4.54 & 0.003 \\
\hline & Earthquake & $-1,198,929.00$ & $227,417.00$ & -5.27 & $<0.001$ \\
\hline & Time $\times$ earthquake & $52,266.00$ & 9704.82 & 5.39 & $<0.001$ \\
\hline \multirow{4}{*}{$\begin{array}{c}\text { Over } 60 \text { years old } \\
\left(d f: 2, \chi^{2}: 3.33, p: 0.189\right)\end{array}$} & Intercept & $26,805.00$ & 9193.40 & 2.92 & 0.033 \\
\hline & Time & 3090.24 & 734.85 & 4.21 & 0.006 \\
\hline & Earthquake & $-635,316.00$ & $163,881.00$ & -3.88 & $<0.001$ \\
\hline & Time $\times$ earthquake & $28,286.00$ & 6987.71 & 4.05 & $<0.001$ \\
\hline
\end{tabular}

Notes: $d f$ (degree of freedom); SE (standard error); $t$ ( $t$-statistic value); $p$ (probability value).

Table 3. ARIMA modeling results for the number of tourist arrivals by visiting purpose.

\begin{tabular}{cccccc}
\hline Visiting Purpose & Effect & Estimate & $S E$ & $t$ & $p$ \\
\hline & Intercept & $147,723.00$ & $55,272.00$ & 2.67 & 0.041 \\
Holiday pleasure & Time & 8400.73 & 4333.33 & 1.94 & 0.100 \\
$\left(d f: 2, \chi^{2}: 32.38, p:<0.001\right)$ & Earthquake & $-1,967,124.00$ & 7319.78 & -2.69 & 0.015 \\
& Time $\times$ earthquake & $924,190.00$ & $31,260.00$ & 2.96 & 0.008 \\
\hline Trekking and & Intercept & $83,317.00$ & $10,129.00$ & 8.23 & $<0.001$ \\
mountaineering & Time & 576.40 & 819.46 & 0.70 & 0.503 \\
$\left(d f: 2, \chi^{2}: 1.62, p: 0.450\right)$ & Earthquake & $-1,323,000.00$ & $217,001.00$ & -6.10 & $<0.001$ \\
& Time $\times$ earthquake & $55,862.00$ & 9246.66 & 6.04 & $<0.001$ \\
\hline & Intercept & $22,255.00$ & 1536.96 & 14.48 & $<0.001$ \\
Business & Time & 30.12 & 125.38 & 0.24 & 0.812 \\
$\left(d f: 2, \chi^{2}: 1.81, p: 0.180\right)$ & Earthquake & $240,224.00$ & $42,740.00$ & 5.62 & $<0.001$ \\
& Time $\times$ earthquake & $-10,719.00$ & 1820.15 & -5.89 & $<0.001$ \\
\hline Pilgrimage & Intercept & -6772.37 & 5009.87 & -1.35 & 0.193 \\
& Time & 4259.49 & 409.20 & 10.41 & $<0.001$ \\
$\left(d f: 2, \chi^{2}: 4.99, p: 0.082\right)$ & Earthquake & $-1,129,281.00$ & $138,615.00$ & -8.15 & $<0.001$ \\
& Time $\times$ earthquake & $48,451.00$ & 5903.09 & 8.21 & $<0.001$ \\
\hline & Intercept & $16,683.00$ & 2385.98 & 6.99 & $<0.001$ \\
& Time & 665.29 & 194.10 & 3.43 & 0.008 \\
Official & Earthquake & $192,201.00$ & $57,957.00$ & 3.32 & 0.003 \\
& Time $\times$ earthquake & -9098.70 & 2468.80 & -3.69 & $<0.001$ \\
\hline & & & &
\end{tabular}


Table 3. Cont.

\begin{tabular}{cccccc}
\hline Visiting Purpose & Effect & Estimate & $S E$ & $t$ & $p$ \\
\hline & Intercept & $22,970.00$ & $136,892.00$ & 1.68 & 0.136 \\
Others & Time & 2461.07 & 1098.53 & 2.24 & 0.056 \\
$\left(d f: 2, \chi^{2}: 13,1, p: 0.001\right)$ & Earthquake & $-219,501.00$ & $241,259.00$ & -0.91 & 0.373 \\
& Time $\times$ earthquake & 9538.58 & $10,287.00$ & 0.93 & 0.365 \\
\hline
\end{tabular}

Notes: $d f$ (degree of freedom); $S E$ (standard error); $t$ ( $t$-statistic value); $p$ (probability value).

The economic indicators of Nepal from 1995 to 2018 are shown in Figure 3 and Table 4. Both tourism receipts and GDP had steadily increased since 1995, but both indicators slightly decreased during the year of the earthquake and the following year (2015-2016). Beginning in 2017, tourism receipts and GDP increased exponentially with a higher rate than in the previous years. Such rapid increase after the earthquake was confirmed by the results of ARIMA modeling. Specifically, the interaction between year and earthquake was significant for tourism receipts $(p<0.01)$ and for GDP $(p<0.001)$, indicating that there were significantly larger increases after the earthquake. The simple slopes derived from the model parameter estimates showed that the difference in the average yearly gain before and after the earthquake was 199.19 for tourism receipts and 2935.1 for GDP (both in millions, U.S. dollar).

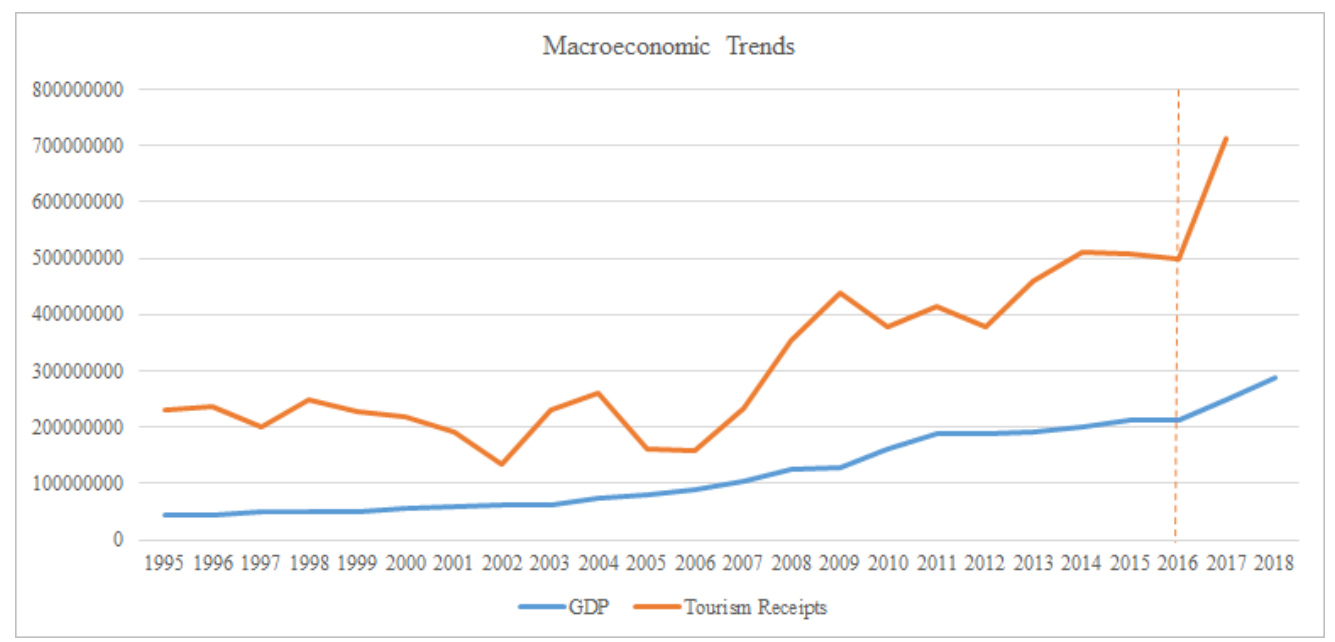

Figure 3. Tourism receipts and GDP in Nepal from 1995 to 2018. GDP is in hundreds. The red dotted line indicates one year after the earthquake (2016).

Table 4. ARIMA modeling results for the macroeconomic trends.

\begin{tabular}{cccccc}
\hline Economic Indicator & Effect & $\begin{array}{c}\text { Estimate } \\
\text { (in Million) }\end{array}$ & $\begin{array}{c}S E \\
\text { (in Million) }\end{array}$ & $t$ & $p$ \\
\hline GDP & Intercept & 2548.20 & 1540.10 & 1.65 & 0.177 \\
$\left(d f: 2, \chi^{2}: 34.09\right.$, & Time & 878.19 & 177.70 & 7.46 & $<0.001$ \\
$p:<0.001)$ & Earthquake & $-61,400.00$ & $14,682.00$ & -4.18 & $<0.001$ \\
& Time $\times$ earthquake & 2935.10 & 670.27 & 4.38 & $<0.001$ \\
\hline \multirow{2}{*}{ Tourism receipts } & Intercept & 152.81 & 45.62 & 3.35 & 0.020 \\
$\left(d f: 2, \chi^{2}: 13.53, p: 0.001\right)$ & Time & 14.81 & 3.79 & 3.91 & 0.008 \\
& Earthquake & -4149.00 & 1198.60 & -3.46 & 0.003 \\
& Time $\times$ earthquake & 199.99 & 55.77 & 3.57 & 0.002 \\
\hline
\end{tabular}

Notes: $d f$ (degree of freedom); $S E$ (standard error); $t$ (t-statistic value); $p$ (probability value). 


\section{Discussion and Conclusions}

This study employed ARIMA with OLS modeling with time series data to analyze the impact of earthquakes on tourism. Specifically, the study revealed some interesting results by comparing preand post-earthquake indicators in terms of tourism demand by age groups and visitation purposes, tourism receipts, and GDP. With the results from this study, tourism destinations can better prepare for the repercussions from natural disasters and overcome challenges to regain stability. Most importantly, destinations with abundant natural and cultural resources are heavily reliant on tourism for employment and GDP. Due to the importance of the tourism industry in Nepal, it is critical to examine the effects of natural disaster, and this also helps to guide the tourism authority to cope with the post-earthquake effects with proper management and marketing efforts.

One of the major findings from this study was that tourism arrivals for four age groups (16-30, $30-45,45-60,60$ and older) significantly decreased immediately after the earthquake but quickly recovered from the drop. The increasing tourism demand for these groups continued throughout 2016 and surpassed the peak in 2014. For ages 0-15, a significant impact of the earthquake was not found, assuming a decreased trend in family travel with children. In regards to tourists' visitation purposes, the demand in business and official segments has not recovered from the earthquake, and this aligns with previous research findings that tourists may see the destination as an unsafe place to travel after catastrophic events, regardless of decreased threats after the incident [48]. In contrast, holiday pleasure, trekking and mountaineering, and pilgrimage segments experienced short-term drops after the earthquakes, but exponential growth in tourism demand followed. This finding was somewhat contrary to other research findings. The demand increase can be explained by a short-term positive impact of reconstruction on tourism arrivals and economic growth [12,13]. However, the tourism demand in Nepal showed a faster recovery time than other regions reported in scholarly research. The Kobe earthquake in 1995, which resulted in a similar number of casualties to the Nepal disaster, had 5-10 years of recovery time [9]. Other studies also indicated that earthquakes exert a negative influence on tourism demand and destination image; thus destinations experience prolonged recoveries [3,27]. Based on these findings, Nepal seems to be a tourism destination with high resilience despite the 7.8 Richter scale earthquake and irreplaceable human casualties.

The findings also revealed that tourism receipts and GDP decreased in 2015 but grew at an exponential rate starting in 2016. Zhu et al. [13] stated that the gap between disaster and economic recovery in severely affected areas tends to be large whereas the proportion of primary, secondary, and tertiary industries also determines the economic recovery. Considering the severity of the earthquake effect in the centralized Kathmandu valley area, it is understandable how overall GDP was severely affected. However, it was interesting to find the amount of tourism receipts decreased in 2016, while the number of tourist arrivals had increased in 2016. This result is possibly due to a reduced average daily rate after the earthquake and destruction of tourism facilities and infrastructure. From 2017 onward, both GDP and tourism receipts increased exponentially due to recovery effects as well as the ripple effects of tourist arrivals (i.e., direct, indirect, and induced effects).

With respect to the considerable magnitude of earthquakes in the center of Nepal destroying multiple tourism sites and resulting in thousands of victims, recovery seemed to be at a faster rate than other similar incidents examined in literature. We propose that one reason could be an increased number of tourists visiting sites that commemorate disasters, often referred to as dark tourism [14]. The massive media coverage during the incident may have increased public interest in the destination. The sense of obligation, curiosity, learning, and emotional reasons are major motivations for people traveling to sites related to catastrophic events [15]. Another reason for the faster recovery would be the unique characteristics of the destination and tourists' visiting purposes. Tourism in Nepal is mostly driven by an interest in natural attractions and religious sites. Therefore, the majority of visitors come to Nepal for holiday pleasure, trekking and mountaineering, and pilgrimage. There is a lack of data that supports the motivations for people traveling to the site. However, these segments may be more resilient in tourism destinations, which allows the destination to quickly bounce back from the disaster. 
This poses an important implication to destinations. Previous research findings may not be applicable to destinations that heavily rely on natural tourism resources. As official trips and group travel were found to have seriously decreased in the study, previous research findings might be mainly due to decreased group and official trips. Tourists' visiting purposes can be a main factor that affects tourism destination resilience in disaster-affected areas.

In conclusion, this study revealed that the extent to which a natural disaster affects tourism and the economy fluctuates widely, which can be attributed to the fact that the contribution depends on characteristics of the destination. The destination is likely to experience a downturn from disasters, but the key factors that significantly influence the degree of tourism destination resilience in disasters may be the country-specific economic composition, tourists' visitation purposes, and type of tourism resources. Additionally, tourism authorities may consider turning the affected areas into tourism attractions to shorten the downturn with the reconstruction effect.

The current study has several limitations. One of the limitations for this study was that the study did not include the repeat visitation variable in the model, therefore interpretations of the findings were inconclusive yet rational. Often, tourism statistics do not include such information. Therefore, we suggest tourism authorities include additional categories to improve data utilization, planning, and development purposes. By collecting additional sociological and visitation information, data utilization for tourists' segmentation and prediction would be easier and assist in marketing and planning purposes. The study included several macroeconomic indicators in the model, but future studies should include other indicators for disasters and recovery, such as exchange rates, oil prices, rate of inflation, prices, etc. It is also recommended to investigate the indicators from visitors' origins and neighboring countries. This study used the data from 1993-2018, which may not be sufficient to determine the long-term impact of earthquakes on destination resilience. Therefore, future studies should adopt longitudinal study approaches in examining destination resilience to the impact of disasters. Lastly, even though this study was able to obtain visitors' age and purpose of the visits, a more detailed dataset of tourists' motivations and demographic information would help identify other reasons behind the boom. This would also help tourism destinations better prepare for unforeseeable events, such as natural disasters, and overcome them with appropriate investments, marketing, and reconstruction strategies to regain stability.

Author Contributions: Conceptualization, J.M.; methodology, S.K. and J.L.; formal analysis, S.K. and J.L.; investigation, J.M.; writing — original draft preparation, J.M. and B.K.C.; writing-review and editing, J.M., B.K.C. and J.L. All authors have read and agreed to the published version of the manuscript.

Funding: This research received no external funding.

Conflicts of Interest: The authors declare no conflict of interest.

\section{References}

1. Weiss-Dagan, S.; Itzhaky, H.; Taubman-Ben-Ari, O. Backpackers in the Nepal 2015 earthquake: The contribution of personal and social resources to mental health. J. Community Psychol. 2018, 46, 689-700. [CrossRef]

2. Nepal Tourism Statistics 2018. Available online: https://tourism.gov.np/files/statistics/19.pdf (accessed on 10 July 2019).

3. Hochrainer, S. Macroeconomic Risk Management against Natural Disasters: Analysis Focused on Governments in Developing Countries; Deutscher Universitäts-Verlag: Wiesbaden, Germany, 2006.

4. Mendoza, C.A.; Brida, J.G.; Garrido, N. The impact of earthquakes on Chile's international tourism demand. J. Policy Res. Tour. Leis. Events 2012, 4, 48-60. [CrossRef]

5. Durocher, J. Recovery marketing: What to do after a natural disaster. Cornell Hotel. Restaur. Adm. Q. 1994, 35, 66-71. [CrossRef]

6. Faulkner, B. Towards a framework for tourism disaster management. Tour. Manag. 2001, 22, $135-147$. [CrossRef] 
7. Sainaghi, R.; Baggio, R. Structural social capital and hotel performance: Is there a link? Int. J. Hosp. Manag. 2014, 37, 99-110. [CrossRef]

8. Travel and Tourism Economic Impact 2019 World. Available online: https://www.wttc.org/-/media/files/ reports/economic-impact-research/regions-2019/world2019.pdf (accessed on 20 February 2020).

9. Chang, S.E. Urban disaster recovery: A measurement framework and its application to the 1995 Kobe earthquake. Disasters 2010, 34, 303-327. [CrossRef]

10. Raddatz, C. Are external shocks responsible for the instability of output in low-income countries? J. Dev. Econ. 2007, 84, 155-187. [CrossRef]

11. Pizam, A.; Smith, G. Tourism and Terrorism: A Quantitative Analysis of Major Terrorist Acts and Their Impact on Tourism Destinations. Tour. Econ. 2000, 6, 123-138. [CrossRef]

12. Xiao, Y. Local Economic Impacts of Natural Disasters. J. Reg. Sci. 2011, 51, 804-820. [CrossRef]

13. Zhu, Y.; Wang, Y.; Liu, T.; Sui, Q. Assessing macroeconomic recovery after a natural hazard based on ARIMA-A case study of the 2008 Wenchuan earthquake in China. Nat. Hazards 2018, 91, 1025-1038. [CrossRef]

14. Stone, P. Dark tourism and the cadaveric carnival: Mediating life and death narratives at Gunther von Hagens' Body Worlds. Curr. Issues Tour. 2011, 14, 685-701. [CrossRef]

15. Cohen, E. Death in paradise: Tourist fatalities in the tsunami disaster in Thailand. Curr. Issues Tour. 2009, 12, 183-199. [CrossRef]

16. Kang, E.J.; Scott, N.; Lee, T.J.; Ballantyne, R. Benefits of visiting a 'dark tourism' site: The case of the Jeju April 3rd Peace Park, Korea. Tour. Manag. 2012, 33, 257-265. [CrossRef]

17. Robb, E.M. Violence and Recreation: Vacationing in the Realm of Dark Tourism. Anthr. Humanism 2009, 34, 51-60. [CrossRef]

18. Ketter, E. Destination image restoration on facebook: The case study of Nepal's Gurkha Earthquake. J. Hosp. Tour. Manag. 2016, 28, 66-72. [CrossRef]

19. Beirman, D.; Upadhayaya, P.K.; Pradhananga, P.; Darcy, S. Nepal tourism in the aftermath of the April/May 2015 earthquake and aftershocks: Repercussions, recovery and the rise of new tourism sectors. Tour. Recreat. Res. 2018, 43,1-11. [CrossRef]

20. Wearing, S.; Beirman, D.; Grabowski, S. Engaging volunteer tourism in post-disaster recovery in Nepal. Ann. Tour. Res. 2020, 80, 102802. [CrossRef]

21. Wang, J.; Luo, X. Resident perception of dark tourism impact: The case of Beichuan County, China. J. Tour. Cult. Chang. 2017, 16, 1-19. [CrossRef]

22. Kunwar, R.R.; Aryal, D.R.; Karki, N. Dark Tourism: A Preliminary Study of Barpak and Langtang as Seismic Memorial Sites of Nepal. J. Tour. Hosp. Educ. 2019, 9, 88-136. [CrossRef]

23. Hochrainer, S. Assessing the Macroeconomic Impacts of Natural Disasters: Are There Any? Policy Research working paper ; no. WPS 4968; World Bank: Washington, DC, USA, 2009. [CrossRef]

24. Huang, J.-H.; Min, J.C. Earthquake devastation and recovery in tourism: The Taiwan case. Tour. Manag. 2002, 23, 145-154. [CrossRef]

25. Tsai, C.H.; Chen, C.W. An earthquake disaster management mechanism based on risk assessment information for the tourism industry-A case study from the island of Taiwan. Tour. Manag. 2010, 31, 470-481. [CrossRef]

26. Guo, Y.; Zhang, J.; Zhang, Y.; Zheng, C. Catalyst or Barrier? The Influence of Place Attachment on Perceived Community Resilience in Tourism Destinations. Sustainability 2018, 10, 2347. [CrossRef]

27. Mair, J.; Ritchie, B.W.; Walters, G. Towards a research agenda for post-disaster and post-crisis recovery strategies for tourist destinations: A narrative review. Curr. Issues Tour. 2014, 19, 1-26. [CrossRef]

28. Mazzocchi, M.; Montini, A. Earthquake effects on tourism in central Italy. Ann. Tour. Res. 2001, 28, 1031-1046. [CrossRef]

29. Rucińska, D. Natural disaster tourism as a type of dark tourism. Int. J. Human. Soc. Sci. 2016, 10, 1458-1462.

30. Lennon, J.J.; Foley, M. Dark Tourism: The Attraction of Death and Disaster; Cengage: Boston, MA, USA, 2001.

31. Iliev, D. Consumption, motivation and experience in dark tourism: A conceptual and critical analysis. Tour. Geogr. 2020, 1-22. [CrossRef]

32. Light, D. Progress in dark tourism and thanatourism research: An uneasy relationship with heritage tourism. Tour. Manag. 2017, 61, 275-301. [CrossRef]

33. Stone, P.; Sharpley, R. Consuming dark tourism: A Thanatological Perspective. Ann. Tour. Res. 2008, 35, 574-595. [CrossRef] 
34. Biran, A.; Poria, Y.; Oren, G. Sought experiences at (dark) heritage sites. Ann. Tour. Res. 2011, 38, $820-841$. [CrossRef]

35. Preece, T.; Price, G.G. Motivations of Participants in Dark Tourism: A Case Study of Port Arthur, Tasmania, Australia. In Taking Tourism to the Limits; Routledge: Abingdon-on-Thames, UK, 2005; pp. 191-198.

36. Biran, A.; Liu, W.; Li, G.; Eichhorn, V. Consuming post-disaster destinations: The case of Sichuan, China. Ann. Tour. Res. 2014, 47,1-17. [CrossRef]

37. Zhang, H.; Yang, Y.; Zheng, C.; Zhang, J. Too dark to revisit? The role of past experiences and intraersonal constraints. Tour. Manag. 2016, 54, 452-464. [CrossRef]

38. Podoshen, J.S.; Yan, G.; Andrzejewski, S.A.; Wallin, J.; Venkatesh, V. Dark tourism, abjection and blood: A festival context. Tour. Manag. 2018, 64, 346-356. [CrossRef]

39. Biran, A.; Buda, D.M. Unravelling Fear of Death Motives in Dark Tourism. In The Palgrave Handbook of Dark Tourism Studies; Springer Science and Business Media LLC: Berlin/Heidelberg, Germany, 2018; pp. 515-532.

40. Hallegatte, S. Economic Resilience: Definition and Measurement. In Policy Research Working Paper; No. 6852; World Bank: Washington, DC, USA, 2014.

41. Zissimopoulos, J.; Karoly, L.A. Employment and Self-employment in the Wake of Hurricane Katrina. Demography 2010, 47, 345-367. [CrossRef] [PubMed]

42. Haque, T.H.; Haque, M.O. The swine flu and its impacts on tourism in Brunei. J. Hosp. Tour. Manag. 2018, 36, 92-101. [CrossRef]

43. Fomby, T.; Ikeda, Y.; Loayza, N.V. The Growth Aftermath of Natural Disasters. J. Appl. Econ. 2009, $28,412$. [CrossRef]

44. Choi, D.W.; Lee, S.; Singal, M. An exploratory temporal analysis of the lodging market and state economic recovery from Hurricane Sandy (The lodging market recovery from Hurricane Sandy). Int. J. Contemp. Hosp. Manag. 2019, 31, 2074-2094. [CrossRef]

45. Hair, J.F. Multivariate Data Analysis, 8th ed.; Cengage: Andover, Hampshire, UK, 2019.

46. Kuo, H.I.; Chen, C.C.; Tseng, W.C.; Ju, L.F.; Huang, B.W. Assessing impacts of SARS and Avian Flu on international tourism demand to Asia. Tour. Manag. 2008, 29, 917-928. [CrossRef]

47. Yang, W.; Wang, D.; Chen, G. Reconstruction strategies after the Wenchuan Earthquake in Sichuan, China. Tour. Manag. 2011, 32, 949-956. [CrossRef]

48. Bonham, C.; Edmonds, C.; Mak, J. The Impact of 9/11 and Other Terrible Global Events on Tourism in the United States and Hawaii. J. Travel Res. 2006, 45, 99-110. [CrossRef] 